\title{
Marine Phytoplankton Improves Exercise Recovery in Humans and Activates Repair Mechanisms in Rats
}

\section{(9) $\circledast \Theta$}

Authors

Matthew H. Sharp ${ }^{1} \mathbb{D}$, Kazim Sahin², Matt W. Stefan ${ }^{1}$, Raad H. Gheith ${ }^{1}$, Dallen D. Reber ${ }^{1}$, Charlie R. Ottinger ${ }^{1}$, Cemal Orhan ${ }^{2}$, Mehmet Tuzcu ${ }^{3}$, Nurhan Sahin ${ }^{2}$, Ryan P. Lowery ${ }^{1}$, Shane Durkee ${ }^{4}$, Jacob M. Wilson ${ }^{1}$

\section{Affiliations}

1 Research Department, Applied Science \& Performance Institute, Tampa, United States

2 Department of Animal Nutrition, Firat University School of Veterinary Medicine, Elazig, Turkey

3 Faculty of Science, Department of Biology, Firat University, Elazig, Turkey

4 Department of Consumer Health, Lonza Inc, Morristown, United States

Key words

overreaching, satellite cells, myostatin, recovery,

resistance-training, performance

accepted 12.11.2020

published online 22.12 .2020

Bibliography

Int J Sports Med 2021; 42: 1070-1082

DOI 10.1055/a-1320-1061

ISSN $\quad 0172-4622$

(c) 2020. The Author(s).

This is an open access article published by Thieme under the terms of the Creative Commons Attribution-NonDerivative-NonCommercial-License, permitting copying and reproduction so long as the original work is given appropriate credit. Contents may not be used for commercial purposes, or adapted, remixed, transformed or built upon. (https://creativecommons. org/licenses/by-nc-nd/4.0/)

Georg Thieme Verlag KG, Rüdigerstraße 14,

70469 Stuttgart, Germany

Correspondence

Matthew H. Sharp

Research Department

Applied Science \& Performance Institute

5850 W. Cypress St

33607 Tampa

United States

Tel.: + 18136738888, Fax : + 18136738888

msharp@theaspi.com

\section{ABSTRACT}

This study investigated the effects of marine phytoplankton supplementation on 1) perceived recovery and ground reaction forces in humans following a non-functional overreaching resistance-training program and 2) myogenic molecular markers associated with muscle cell recovery in a rat model. In the human trial, a 5-week resistance-training program with intentional overreaching on weeks 2 and 5 was implemented. Results indicate that marine phytoplankton prompted positive changes in perceived recovery at post-testing and, while both marine phytoplankton and placebo conditions demonstrated decreased peak and mean rate of force development following the overreaching weeks, placebo remained decreased at posttesting while marine phytoplankton returned to baseline levels. In the rat model, rats were divided into four conditions: (i) control, (ii) exercise, (iii) exercise + marine phytoplankton 2.55 $\mathrm{mg} \cdot \mathrm{d}^{-1}$, or (iv) exercise + marine phytoplankton $5.1 \mathrm{mg} \cdot \mathrm{d}^{-1}$. Rats in exercising conditions performed treadmill exercise $5 \mathrm{~d} \cdot \mathrm{wk}^{-1}$ for 6 weeks. Marine phytoplankton in exercising rats increased positive and decrease negative myogenic factors regulating satellite cell proliferation. Taken together, marine phytoplankton improved perceptual and functional indices of exercise recovery in an overreaching human model and, mechanistically, this could be driven through cell cycle regulation and a potential to improve protein turnover. 


\section{Introduction}

Anaerobic exercise increases force and power output in a volume-, intensity-, and frequency-dependent manner [1]. According to classic Adaptation Theory, exercise stress yields a general adaptation response that is triggered by a disruption in homeostasis [2]. Following this disruption, an increase in biological function occurs which protects against future bouts of exercise stress [1]. Imbalances between the exercise stimulus and recovery may disrupt these adaptations and place an athlete or trainee in a maladapted state [3]. Extended periods of intensified exercise can result in an accumulation of fatigue, leading to short-term (overreaching) and long-term (overtraining) decrements in the ability to perform [3]. These outcomes have been confirmed in various athlete types including rugby [4], soccer [5, 6], basketball [7], American football [8], and triathletes [9].

Excessive exercise may contribute to disturbances in biological function through physiological deregulation that leads to impairments in function and recovery [10]. From a molecular standpoint, this deregulation of recovery is controlled by a complex array of myogenic regulatory factors that drive satellite cell activation, differentiation, and replenishment $[11,12]$. Indeed, research has indicated satellite cells as the key variable driving recovery from exercise $[13,14]$. Impairment in the recruitment of these cells ultimately leads to a failing ability to compensate for training load-induced stress $[13,15]$. Key positive regulators of satellite cell cycle progression include myogenic differentiation factor (MyoD) and neural cell adhesion molecule (NCAM), a multifunctional cellsurface protein that has been found to drive muscle recovery [16]. In contrast, myostatin impairs muscle recovery by inhibiting satellite cell progression and increasing protein breakdown [17].

Chronic molecular changes are eventually reflected in performance outcomes [16]. One of the major areas impacted during overreaching and overtraining scenarios is explosive strength [18]. Explosive strength is the speed or rate an athlete can develop force [19]. This motor ability predicts performances of both sportspecific and functional daily tasks to a greater degree than maximal strength, which is seldom expressed in the time constraints of sport or daily activity [19]. Moreover, this measure has been determined to be more sensitive to detect acute (24-72 hrs) [18] and chronic (> 4 wk) $[16,20]$ changes in neuromuscular function as compared to non-time constrained maximal strength measures. In addition, overreaching leads to impaired readiness to train, which is also termed "perceived recovery." Perceived recovery is strongly predictive of multiple indices of performance and biochemical related measures of recovery [21,22]. As such, perceived recovery is a validated tool for determining whether an individual is recovered.

While coaches find it challenging to change the demands of a season, they may alter their athletes' responses through the consumption of supplements that are rich in ingredients capable of influencing recovery. Dietitians have made a push for natural, sustainable superfoods, which contain an array of performance aids [23]. In response, scientists have isolated a unique source of marine phytoplankton (microalga Tetraselmis chuii), which contains highly active superoxide dismutase (SOD). Our previous research found that marine phytoplankton was able to robustly increase intramuscular antioxidant enzymes, lower muscle damage, and sustain anaerobic performance in a short term (3 days) repeated high- intensity competition style challenge [24]. However, the effects on long-term recovery of this natural marine-derived ingredient remain to be investigated. Therefore, the purpose of this study was to investigate the effects of targeted marine phytoplankton supplementation on recovery as assessed through perceived recovery, explosive strength, and ground reaction forces that are pertinent to anaerobic performance. While we previously reported significant long-term improvements in antioxidant status [24], we wanted to further explore the impact of this ingredient on regenerative pathways. Therefore, a secondary purpose of this study was to determine the effects of this ingredient on myogenic molecular markers known to promote muscle recovery $[11,12]$ using a rat model. Finally, we assessed the long-term safety of marine phytoplankton supplementation. We hypothesized that marine phytoplankton would enhance recovery from 5 weeks of training meant to induce non-functional overreaching, and that it would simultaneously increase positive and decrease negative regulators of satellite cell progression, respectively. We also hypothesized that the ingredient would be safe for human consumption.

\section{Materials and Methods}

\section{Human Trial}

\section{Subjects}

Male and female subjects were recruited by word of mouth, email contact, and direct website inquiries from online advertisement. Subjects were excluded from the study if they: had a body mass index $(\mathrm{BMI}) \geq 30 \mathrm{~kg} / \mathrm{m}^{2}$, have allergies to fish, shellfish, algae, or seaweed; have any cardiovascular, metabolic, or endocrine disease; have undergone surgery that affects digestion and absorption, smoke, drink heavily ( $>7$ and > 14 drinks per week for women and men, respectively), were pregnant or planning to be pregnant, were on medication to regulate blood glucose, lipids, and/or blood pressure; have used anabolic-androgenic steroids, were currently using antioxidant supplements, non-steroidal anti-inflammatory drugs, or nutritional supplements known to stimulate recovery or muscle mass accretion. For inclusion, subjects were required to be between 18-45 years old and have continuously exercised for the past year a minimum of 3 days week ${ }^{-1}$, achieving 30 min of vigorous activity ( $\geq 75 \%$ age-predicted maximum heart rate) per session.

To determine sample size for the study, an a priori power analysis (G * Power, 3.0.10, Universität, Germany) was carried out with the given $\alpha$, power and effect size values. The test family was set as F-test and the statistical test was set as a repeated-measures analysis of variance (ANOVA) inputting the following parameters: $\alpha=0.05 ; 1-\beta=0.8$; effect size $=0.5$; number of groups $=2$; repetitions $=4$. In our previous investigation on the same marine phytoplankton ingredient (microalga Tetraselmis chuii), we observed an effect size of 0.54 and 0.65 on performance metrics in the countermovement and squat jump, respectively [24]. Thus, we believe the effect size estimation of 0.5 for the power analysis was practical. The resulting outcome parameters indicated a total sample size of 22 , equating to 11 subjects per group. In total, 26 subjects enrolled for participation in the study. Three subjects were lost, due to unforeseen time constraints and one due to a family bereavement prior to completion of the study. Therefore, descriptive statistics were re- 
- Table 1 Baseline descriptive statistics.

\begin{tabular}{|c|c|c|c|c|}
\hline Variable & MP $(n=12 ; m=6, f=6)$ & $\operatorname{PLA}(n=10 ; m=5, f=5)$ & Total $(\mathrm{N}=22)$ & $p$-value \\
\hline Age (yrs) & $29.2 \pm 2.1$ & $29.2 \pm 2.0$ & $29.2 \pm 1.5$ & 0.981 \\
\hline Height $(\mathrm{cm})$ & $173.7 \pm 3.4$ & $173.6 \pm 2.5$ & $173.6 \pm 2.1$ & 0.989 \\
\hline Body Mass $(\mathrm{kg})$ & $74.0 \pm 5.4$ & $78.9 \pm 4.9$ & $76.1 \pm 3.7$ & 0.522 \\
\hline Fat-Free Mass $(\mathrm{kg})$ & $55.4 \pm 4.5$ & $59.4 \pm 4.2$ & $57.2 \pm 3.1$ & 0.536 \\
\hline Fat Mass $(\mathrm{kg})$ & $18.6 \pm 1.9$ & $19.5 \pm 1.9$ & $19.0 \pm 1.3$ & 0.737 \\
\hline Body Fat (\%) & $25.4 \pm 2.1$ & $24.8 \pm 2.2$ & $25.1 \pm 1.5$ & 0.850 \\
\hline BMI $\left(\mathrm{kg} / \mathrm{m}^{2}\right)$ & $24.2 \pm 1.0$ & $26.0 \pm 1.2$ & $25.0 \pm 1.0$ & 0.278 \\
\hline
\end{tabular}

- Table 2 Nutrient profile for microalga Tetraselmis chuii.

\begin{tabular}{|l|l|}
\hline Variable & Value \\
\hline Kcal $\cdot \mathrm{g}^{-1}$ & 3.37 \\
\hline Fat $(\%)$ & 8.0 \\
\hline Carbohydrate $(\%)$ & 52.0 \\
\hline Protein $(\%)$ & 40.0 \\
\hline Vitamin $\mathrm{E}(\mathrm{\mu g} / \mathrm{g})$ & 520 \\
\hline Vitamin $\mathrm{C}(\mathrm{\mu g} / \mathrm{g})$ & 3333 \\
\hline Potassium $(\mathrm{mg} / \mathrm{g})$ & 10.4 \\
\hline Magnesium $(\mathrm{mg} / \mathrm{g})$ & 5.06 \\
\hline Calcium $(\mathrm{mg} / \mathrm{g})$ & 33.8 \\
\hline Nutritional data per gram of microalga Tetraselmis chuii. \\
\hline
\end{tabular}

ported for the 22 subjects that completed the trial ( $\vee$ Table 1 ). Prior to engaging in any study procedures, subjects signed a written informed consent for participation that was approved by an Institutional Review Board (IntegReview, Austin, TX) and in agreement with the Declaration of Helsinki. The study is in accordance with the ethical standards of the International Journal of Sports Medicine [25].

\section{Study design}

This study was carried out in a randomized, double-blind, placebocontrolled, parallel manner. Prior to allocation into conditions, subjects were assessed for body composition via whole-body, dual-energy $x$-ray absorptiometry (DXA) scan. Subjects were then classified into quartiles according to fat-free mass, and subjects from each quartile were randomly assigned to conditions. Following condition allocation, subjects underwent baseline testing on day 0 (Pre) which included: blood sample donation, force plate countermovement jump, and perceptual measures of the Perceived Recovery Status scale. Force plate countermovement jump assessments were subsequently performed upon subject arrival to the laboratory for the last training session of week 2 (Wk2-Post) and week 5 (Wk5-Post), and the final day of week 6 (Post). Blood samples were donated again at Post. The Perceived Recovery Status scale was assessed on each training day throughout the study and averaged for the week.

\section{Dual-Energy X-ray absorptiometry}

Upon arriving to the laboratory following an overnight fast ( $10 \mathrm{~h})$, subjects were instructed to void to eliminate any flatus in the gas- trointestinal tract and urine in the bladder. Thereafter, body mass to the nearest $0.1 \mathrm{~kg}$ and height to the nearest $\mathrm{cm}$ were measured with a digital scale and stadiometer, respectively (Seca, Chino, CA). A whole-body scan on a dual-energy X-ray absorptiometry device (Horizon A DXA System, Hologic Inc, Marlborough, MA) was performed with the subject lying in a supine position with knees and elbows extended. Subjects were instructed not to move for the entire duration of the scan (approximately $5 \mathrm{~min}$ ). The DXA has a switching-pulse system that rapidly alternates the voltage of the $\mathrm{X}$-ray generator, producing two beams of high and low energies. The attenuated $\mathrm{X}$-rays that have passed through the subject are measured sequentially with a detector situated on the scanning arm above the patient. An internal wheel corrects for any small fluctuations caused by this method of beam generation. Results from each scan were uploaded and accessed on a computer that was directly linked to the DXA device. Calibration of the DXA device was done against a phantom provided by the manufacturing company prior to testing.

\section{Supplement protocol}

Following random assignment, subjects were given either marine phytoplankton (MP) (Tetraselmis chuii; Oceanix ${ }^{\mathrm{TM}}$, Lonza Consumer Health Inc; Morristown, NJ, USA) or microcrystalline cellulose-based placebo (PLA). - Table 2 provides nutritional information for the Tetraselmis chuii product used in the study, which was also independently examined by Brunswick Laboratories (Southborough, MA, USA) for Oxygen Radical Absorbance Capacity (ORAC) expressed in micromole Trolox equivalency ( $\mu$ mole TE) per gram. The results indicated that values were high for hydroxyl radicals at 178.71 $\mu$ mole TE/gram and super oxide anions at $348.11 \mu$ mole TE/gram, moderate in peroxynitrite and peroxyl radicals at 8.65 and 29.65 $\mu$ mole TE/gram, respectively, and not detectable in singlet oxygen and hypochlorite. The ORAC values for the super oxide anion corresponded with high total values (38000 IU per $100 \mathrm{grams}$ ) of SOD in raw powder measured. Conditions were stored in visually identical capsules and containers. Subjects were required to consume one serving $(25 \mathrm{mg})$ a day, either 30 min prior to exercise or with the first meal of the day on non-exercise days. Supplement compliance was assessed by supplement logs and collection of supplement containers. Subjects were instructed to refrain from consuming any nutritional supplements for the duration of the study. 


\section{Resistance training protocol}

All subjects completed a 5-week resistance training program. Resistance training sessions were completed $3 \mathrm{~d} \cdot \mathrm{wk}^{-1}$ during weeks 1,3 , and 4 while week 2 and week 5 increased to $5 \mathrm{~d} \cdot \mathrm{wk}^{-1}$. Week 1 was a baseline maintenance training week where subjects did not perform at repetition maximum loads. Weeks 2 and 5 were programmed to induce non-functional overreaching (124 sets - week ${ }^{-1}$ ). Weeks 3 and 4 consisted of moderate volume training. All sets performed during weeks $2-5$ were performed with repetition maximum loads such that sets were either performed to or near muscular failure. Whenever subjects missed the targeted repetition count by 2 or more repetitions, the load was decreased by $5 \%$; similarly, whenever subjects surpassed the targeted repetition count by 2 or more, the load was increased by $5 \%$. Immediately following the completion of all resistance training sessions, subjects completed a cool down consisting of static stretching of the major muscle groups targeted within the resistance training session. All stretches were repeated twice and held for 20 s each. All warm-up, resistance training, and cool down sessions were supervised by a certified strength and conditioning specialist (NSCA-CSCS) who also monitored training loads for each exercise [26]. Whenever five or more subjects were on the training floor at once, two certified strength and conditioning specialists were supervising the training floor. A maximum of ten subjects were allowed on the training floor. A detailed description of the resistance training program is provided in > Table 3. All training sessions were completed with at least 24-h recovery from the previous training session.

\section{Perceived recovery}

Subject responses for perceived recovery were collected using a Perceived Recovery Status (PRS) scale in a manner like Laurent and colleagues [22]. The PRS consists of a scalar representation numbering from 0-10. One the scale, responses of 0-2 are "very poorly recovered" with "expected decline in performance", 4-6 are "low to moderately recovered" and "expected similar performance", and 8-10 represent high perceived recovery with "expected increases in performance". Subjects PRS were recorded following the dynamic warm-up and prior to each training session. Data are reported as weekly averages. Because week one of this study was considered maintenance training, perceived recovery was expressed relative to this week for all other weeks.

\section{Force Plate Countermovement Jump (CMJ)}

Prior to performing a CMJ, subjects completed a warm-up of 10 bodyweight squats and two submaximal effort CMJs. Subjects were instructed to stand in a comfortable and upright position with the feet about shoulder-width apart and parallel to each other. Subjects then performed a countermovement by flexing the hips and knees. Once subjects reached a preferred countermovement depth, they explosively extended their hip, knee, and ankle joints to perform a maximal vertical jump. All CMJs were performed with an arm swing. Subjects performed 2 maximal effort CMJs in this manner separated by 30 s rest. The jump that resulted in the greatest jump height (determined as center of mass displacement) was used for statistical analysis.

The force platform has a length of $66 \mathrm{~cm}$, a width of $66 \mathrm{~cm}$, and a height of $7 \mathrm{~cm}$. The platform was composed of two symmetrical force plates that separate the platform into left and right halves. Each plate contained four strain gauge force sensors (the whole platform thus had eight force sensors). The force sensors measured the magnitude and rate of vertical ground reaction force development exerted on the platform. The sensors were connected to a laptop computer via a USB 2.0 connection. The signals from the force sensors were sampled at a frequency of $800 \mathrm{~Hz}$ and analyzed using the Mechanography GRFP Research Edition ${ }^{\circledR}$ software (in this study version 4.4b01.62 was used).

\section{Blood sampling}

Venous blood was extracted by venipuncture of the antecubital vein using a 21-gauge draw needle and collected into a 10mL EDTA tube (BD Vacutainer ${ }^{\circledR}$, Becton, Dickinson and Company, Franklin Lakes, NJ) by a certified phlebotomist. Afterward, blood samples were centrifuged at $2500 \mathrm{rpm}$ for $10 \mathrm{~min}$ at $4^{\circ} \mathrm{C}$. Resulting serum and plasma samples were then aliquoted and stored at $-80^{\circ} \mathrm{C}$ until analysis. From these samples, the following markers were quantified: general chemistry panel, complete blood count, and automated differential cell count.

\section{Statistical analysis}

Prior to performing statistical analysis, normality was assessed for all dependent variables via Shapiro-Wilk testing and for outliers using visual inspection of box blots. Data passed normality and no outliers were detected. Following outlier and normality testing, dependent variables were scrutinized using a two-way mixed analysis of variance (ANOVA) with condition as the "between-group" factor time as the "within-group" factor and subjects as a random factor. Whenever a significant F-value was obtained, post-hoc testing was performed with a Bonferroni correction for multiple comparisons. For ANOVA procedures, homogeneity of variances and covariances were confirmed by Levene's test and Box's M test, respectively. Additionally, Mauchly's test of sphericity was used to test the assumption of sphericity for two-way interactions. In addition, select variables were expressed as a percentage (100* Time $_{2} /$ Time $_{1}$ ) and analyzed using two-tailed, unpaired $t$-test for between group comparisons. Baseline characteristics were compared between groups with two-tailed, unpaired $t$-test ( $>$ Table 1). Statistical significance was set a priori $\mathrm{p} \leq 0.05$ and data are reported as mean \pm standard error. Data were analyzed using SPSS software (IBM SPSS, Version 26.0; SPSS, Inc., Chicago, IL, USA) and GraphPad Prism 8 software (GraphPad Software, Inc., La Jolla, CA, USA).

\section{Rat Trial}

\section{Rats and protocol}

Male Wistar albino rats ( $n=28,8$ weeks old) were provided from the Laboratory Animal Research Center, Firat University (Elazig, Turkey). The animals were kept at a room with standard conditions $\left(22 \pm 2{ }^{\circ} \mathrm{C}\right.$ temperature, $55 \pm 5 \%$ humidity, a 12 -h light-12-h dark cycle). The ethical permission of the experiment was obtained from the Animal Experimentation Ethics Committee of Firat University (2019/139206) according to the relevant laws, guidelines, and restrictions.

Rats were randomly divided into four groups $(n=7)$ : (i) Control (no exercise and placebo), (ii) Exercise (E), (iii) Exercise + marine phy- 


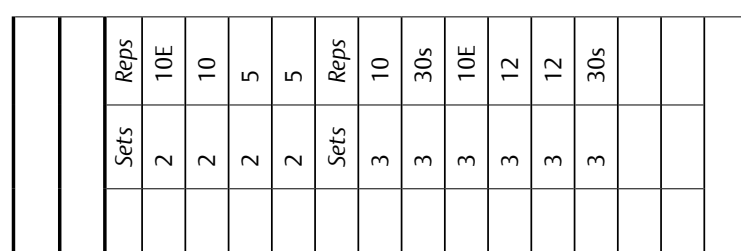

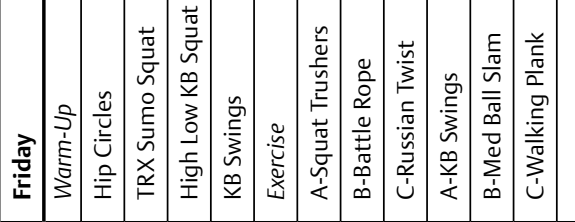

告

\section{高}

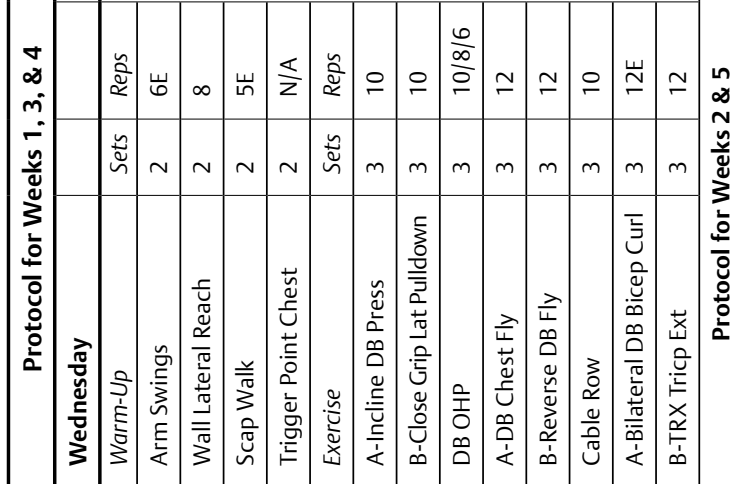

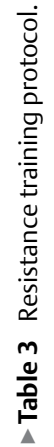

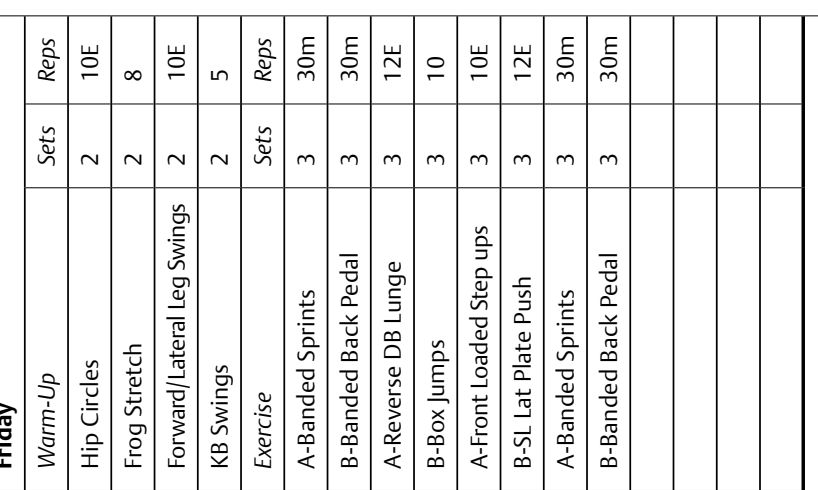

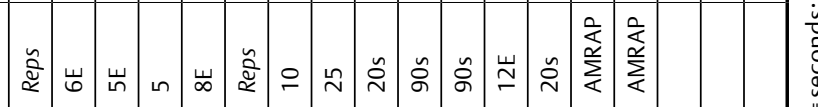

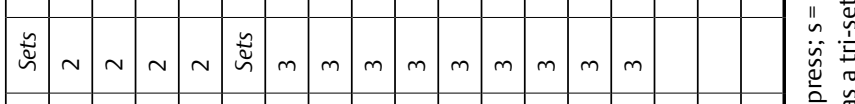

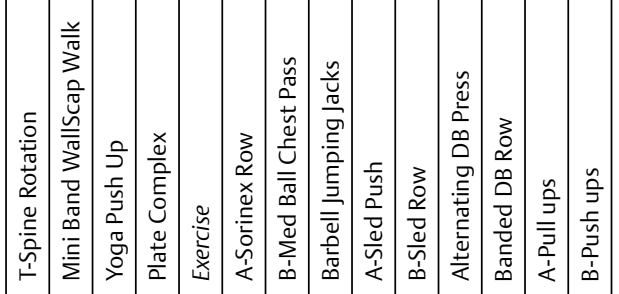

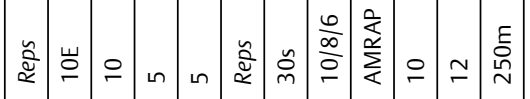

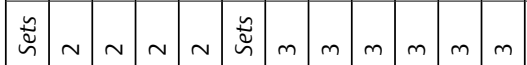

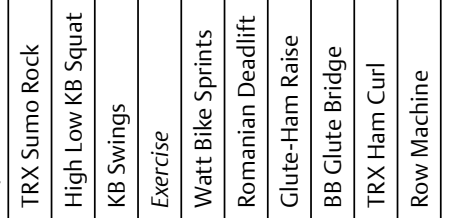

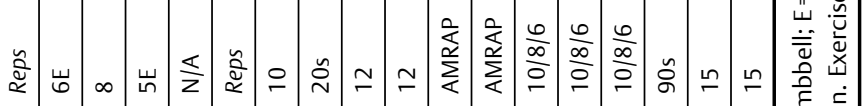

苛 N N

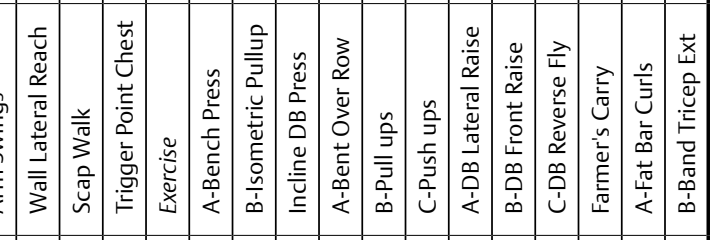

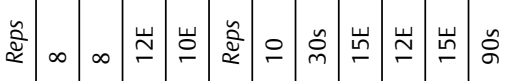

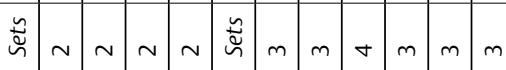

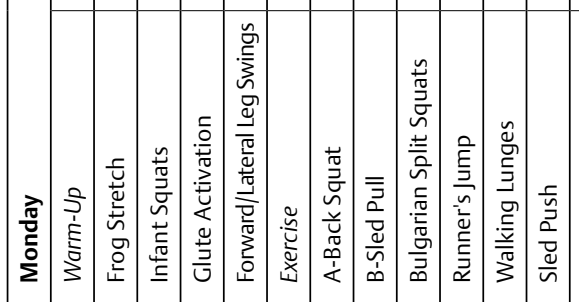


toplankton 1 (2.55 mg $\cdot$ day $^{-1}$, [E + MP1]), (iv) Exercise + marine phytoplankton $2\left(5.1 \mathrm{mg} \cdot \mathrm{day}^{-1}[\mathrm{E}+\mathrm{MP} 2]\right)$. Marine phytoplankton and placebo (physiological saline) were administered orally via gavage every day before exercise during the experiment period ( 6 weeks).

The rats were subjected to treadmill exercise on a motorized rodent treadmill (Commat Limited, Ankara, Turkey). The treadmill contained a stimulus grid at the back end of the treadmill giving an electric shock when the animal placed its paw on the grid. The apparatus had a 5-lane animal exerciser utilizing a single belt unit divided with walls suspended over the tread surface. In order to eliminate the diurnal variations, all exercise tests were applied during the same time of the day. A week of adaptation was provided as pre-training practice for the animals in order to get familiar with the treadmill equipment and handling. In doing so, the rats in the exercise training groups were accustomed by treadmill exercise over 5 days such that: (i) $1 \mathrm{st}$ day, $10 \mathrm{~m} \cdot \mathrm{min}^{-1}, 10 \mathrm{~min}$, (ii) 2 nd day, $20 \mathrm{~m} \cdot \mathrm{min}^{-1}, 10 \mathrm{~min}$, (iii) 3rd day, $25 \mathrm{~m} \cdot \mathrm{min}^{-1}, 10 \mathrm{~min}$, (iv) 4th day, $25 \mathrm{~m} \cdot \mathrm{min}^{-1}, 20 \mathrm{~min}$ and $(\mathrm{v}) 5$ th day, $25 \mathrm{~m} \cdot \mathrm{min}^{-1}, 30 \mathrm{~min}$. Upon an adaptation of a week to the treadmill system for the novel and stress impacts, the rats in treadmill exercise groups ran on the treadmill at $25 \mathrm{~m} \cdot \mathrm{min}^{-1}, 45 \mathrm{~min} \cdot \mathrm{d}^{-1}$ five days per week for 6 weeks according to the protocol described by Liu et al. [27].

At the end of the study, animals in all groups were sacrificed by cervical dislocation under xylazine $\left(10 \mathrm{mg} \cdot \mathrm{kg}^{-1}\right.$, i.m. $)$ and ketamine (50 mg $\cdot \mathrm{kg}^{-1}$, i.m.) anesthesia on the same day; thereafter, blood and gastrocnemius muscle were collected. Serum samples were obtained by taking blood samples to gel biochemical tubes after centrifugation ( $5000 \mathrm{rpm}$ at $4^{\circ} \mathrm{C}$ for $10 \mathrm{~min}$ ). Serum creatine kinase concentrations were assayed using a portable automated chemistry analyzer (Samsung LABGEO PT10, Samsung Electronics Co., Suwon, Korea). Samples of the gastrocnemius muscle (taken from approximately the same location each time) were quickly removed, placed on ice, and kept at $-80^{\circ} \mathrm{C}$ until further analysis.

\section{Western blot analysis}

Muscle samples were pooled and homogenized in $1 \mathrm{ml}$ ice-cold hypotonic buffer A including $10 \mathrm{mM}$ HEPES (pH 7.8), $10 \mathrm{mM} \mathrm{KCl}, 2$ $\mathrm{mM} \mathrm{MgCl}$, 1 mM DTT, $0.1 \mathrm{mM}$ EDTA, and $0.1 \mathrm{mM}$ phenylmethylsulfonyl-fluoride (PMSF). Eighty $\mu$ l of $10 \%$ Nonidet P-40 (NP-40) solution was added to the homogenates and the mixture then was implemented with centrifugation for $2 \mathrm{~h}$ at $14000 \mathrm{~g}$. $500 \mu \mathrm{l}$ of buffer A plus $40 \mu \mathrm{l}$ of $10 \% \mathrm{NP}-40$ was used to wash the precipitates containing nuclei. The precipitates were then centrifuged and resuspended in $200 \mu$ l of buffer C [ $50 \mathrm{mM} \mathrm{HEPES} \mathrm{(pH} \mathrm{7.8),} 50 \mathrm{mM} \mathrm{KCl}$, 300 mM NaCl, 0.1 mM EDTA, 1 mM DTT, 0.1 mM PMSF, 20 \% glycerol], and centrifuged for $30 \mathrm{~min}$ at $14.800 \mathrm{~g}$. The supernatant was removed to new tubes. Western blot analyses were run on the tissue homogenates for MyoD and NCAM for positive regulators of satellite cell progression, and myostatin as a negative regulator of satellite cells and its downstream targets, muscle atrophy F-box (MAFbx) and muscle RING finger 1 (MuRF-1), which increase protein breakdown. Protein concentration was measured using the Lowry method. A pool of tissue samples was created with the same amounts of protein $(50 \mu \mathrm{g})$ and the samples were electrophoresed (12\% SDS-PAGE gels) followed by transfer to nitrocellulose membrane (Schleicher and Schuell Inc., Keene, NH, USA). The primary antibody for beta-actin was delivered (Abcam Inc., UK) and reduced in strength (1:1000) in the same buffer containing $0.05 \%$ Tween-20. The antibody with the nitrocellulose membrane was incubated overnight at $4{ }^{\circ} \mathrm{C}$. After washing, the blots were incubated with goat antimouse IgG (horseradish peroxidase-conjugated secondary antibody) with a dilution of 1:5000 (Abcam, Cambridge, UK). Protein bands were quantified via scanning densitometry using an image analysis system (Image J; National Institute of Health, Bethesda, MD, USA). The protein bands were normalized by the corresponding $\beta$-actin band values and compared with the control group.

\section{Statistical analysis}

Data were presented as the mean \pm SEM. All tests were performed with the SPSS software program (IBM SPSS, Version 22.0; Chicago, IL, USA). Significance was determined by one-way ANOVA. Whenever a significant F-value was obtained, the Tukey HSD post-hoc test was used for multiple comparisons. Statistical significance for data was previously defined as $\mathrm{p}<0.05$.

\section{Results}

\section{Human Trial}

\section{Perceived Recovery Status Scale (PRS)}

Analysis of Perceived Recovery Status (PRS) scale changes relative to Wk1 levels indicated significant within-group differences for MP whereby PRS at Wk6 $(p<0.05, \Delta+1.1,+16 \%$ was greater than $W k 2$ ). Additionally, relative change in PRS from $W k 1$ to $W k 6$ was significantly greater for MP at compared to PLA ( $<<0.05$; MP: $+1.1 \pm 0.4$ a.u., $+16 \%$; PLA: $-0.5 \pm 0.9$ a.u, $-6 \%)$. These results are shown in $>$ Fig. 1.

\section{Force Plate CM]}

Significant group by time interactions were detected for both peak and mean explosive strength (RFD). Post-hoc analysis indicated

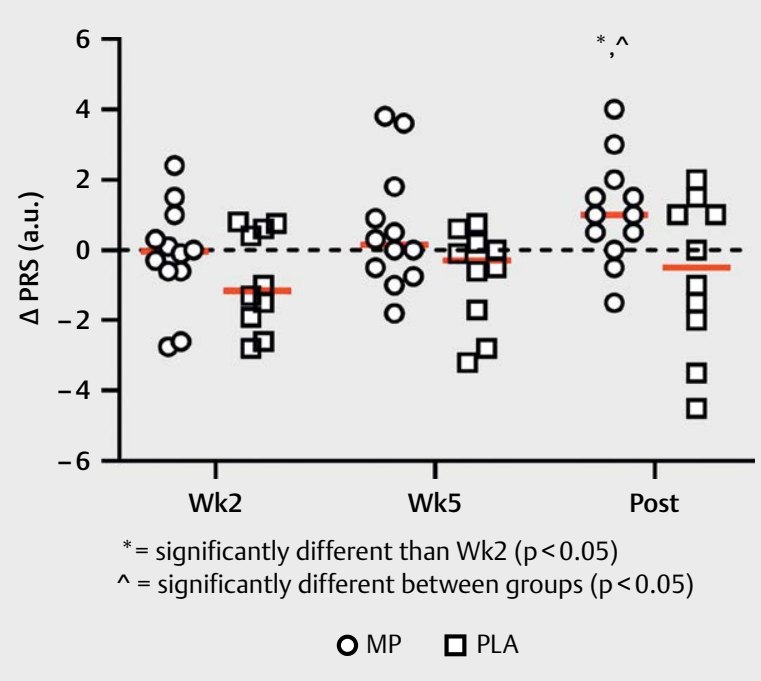

- Fig. 1 PRS Change Relative to Wk1. Changes in Perceived Recovery Status scale relative to Wk1 (Time $2-W k 1)$. Red line indicates mean value. ${ }^{*}=$ Significantly greater than Week $2(p<0.05) .^{\wedge}=$ Significantly different between groups $(\mathrm{p}<0.05)$. 
that both groups experienced decreased peak and mean RFD at Wk2-Post and Wk5-Post ( $<<0.05)$ compared to Pre. However, PLA remained decreased at Post $(p<0.05)$ while MP had returned to Pre levels (98.0\% vs. PLA: $67.7 \%$, > Fig. 2). Furthermore, peak and mean RFD at Post was significantly different between groups $(p<0.05)$. A significant main effect of time was demonstrated for peak force $(p<0.05)$. Post-hoc testing revealed that levels at Wk2Post were significantly lower than Post $(p<0.05)$. The relative Pre to Post change for $\mathrm{H}_{\max } / \mathrm{H}_{\min }$ was significantly different between groups ( $p<0.05$, MP: + 11.3, PLA: -16.1). No significant betweenor within-group differences were detected for jump displacement $(p>0.05,>$ Table 4).

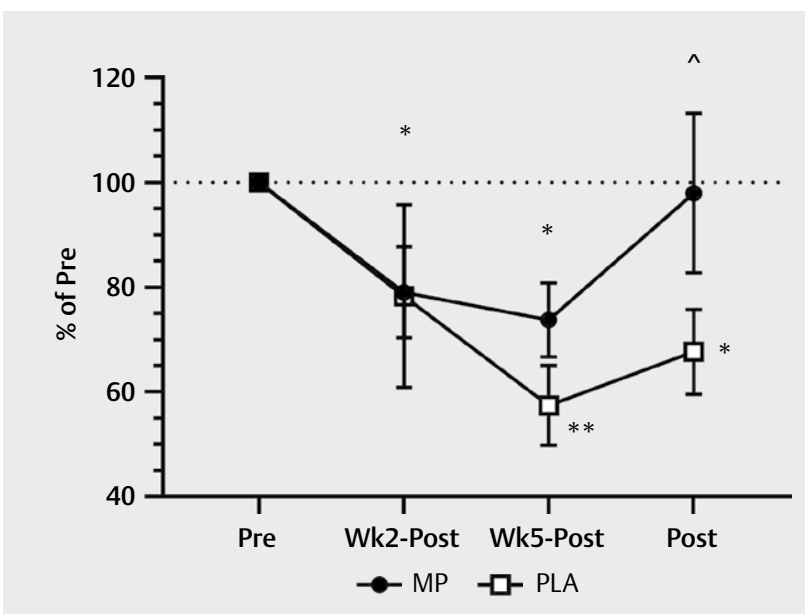

- Fig. 2 Explosive Strength Measured as Mean RFD $\left(\mathrm{kN} \cdot \mathrm{s}^{-1}\right)$. Percentage of Pre-Test value at subsequent timepoints determined as $\left(100{ }^{*}\left(\right.\right.$ Time $_{2} /$ Pre $\left.)\right) .{ }^{*},{ }^{*} *$ significantly lower than Pre $(p<0.05$, $\mathrm{p}<0.01){ }^{\wedge}=$ significantly different between groups $(\mathrm{p}<0.05)$.

\section{Blood safety parameters}

Blood chemistry and hematology analyses were performed at Pre and at the conclusion of the study. Results for comprehensive metabolic panel, complete blood counts, and automated differential cell count are shown in $\triangleright$ Tables 5,6 , and $\triangleright \mathbf{7}$, respectively. No statistically or clinically significant changes were detected in any blood chemistry or hematological variable ( $p>0.05)$. Additionally, no adverse effects due to supplementation were reported in this study.

\section{Rat Trial}

\section{Expression of proteins driving skeletal muscle repair and breakdown}

For the exercise arm and both supplement arms, MAFbx expression was significantly lower than control ( $\triangleright$ Fig. 3a). However, MAFbx expression in both supplement arms was lower than the exercise arm, and E + MP2 was lower than E + MP1 ( $<<0.05)$. For the exercise arm and both supplement arms, MURF-1 expression was significantly depressed compared to control ( $>$ Fig. 3b). Additionally, MURF-1 expression in both supplement arms was lower than the exercise arm $(p<0.05)$. MyoD expression was significantly increased in the exercise arm and both supplement arms compared to control ( $p<0.05$, > Fig. 3c). Moreover, $E+M P 1$ had greater MyoD expression than the exercise and $E+M P 2$ arms $(p<0.05)$. For the exercise and both supplement arms, myostatin expression was significantly lower than control ( $p<0.05$, $>$ Fig. 3b). Additionally, $\mathrm{E}+\mathrm{MP2}$ demonstrated lower myostatin expression than the exercise arm ( $p<0.05$, $>$ Fig. 3c). Expression of NCAM was greater in both supplement arms than the exercise and control arms $(p<0.05$, Fig. 3d).

- Table 4 Ground reaction force parameters during the countermovement jump.

\begin{tabular}{|c|c|c|c|c|}
\hline & Pre & Wk2-Post & Wk5-Post & Post \\
\hline \multicolumn{5}{|c|}{ Peak Force (N) } \\
\hline MP & $1674 \pm 145$ & $1578 \pm 150$ & $1632 \pm 148$ & $1725 \pm 172$ \\
\hline PLA & $1775 \pm 139$ & $1691 \pm 145$ & $1737 \pm 139$ & $1736 \pm 142$ \\
\hline \multicolumn{5}{|c|}{ Peak RFD $\left(\mathrm{N} \cdot \mathrm{s}^{-1}\right)$} \\
\hline MP & $8718 \pm 935$ & $6759 \pm 720^{*}$ & $6300 \pm 886^{*}$ & $8565 \pm 1282^{\wedge}$ \\
\hline PLA & $8973 \pm 1664$ & $7123 \pm 1607^{*}$ & $5047 \pm 719^{* *}$ & $6030 \pm 934^{*}$ \\
\hline \multicolumn{5}{|c|}{ 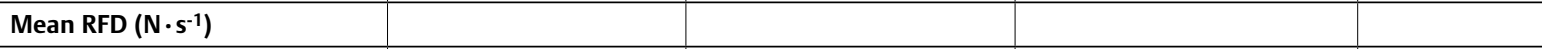 } \\
\hline MP & $3970 \pm 412$ & $3139 \pm 322 *$ & $2929 \pm 386^{*}$ & $3890 \pm 543^{\wedge}$ \\
\hline PLA & $4036 \pm 586$ & $3161 \pm 644^{*}$ & $2318 \pm 294^{* *}$ & $2731 \pm 384^{*}$ \\
\hline \multicolumn{5}{|c|}{ Jump Displacement (cm) } \\
\hline MP & $44.3 \pm 3.3$ & $44.1 \pm 3.0$ & $43.4 \pm 3.5$ & $44.5 \pm 3.6$ \\
\hline PLA & $45.5 \pm 4.7$ & $45.4 \pm 4.1$ & $45.3 \pm 4.0$ & $45.7 \pm 4.4$ \\
\hline \multicolumn{5}{|c|}{$\mathbf{H}_{\max } / \mathbf{H}_{\min }(\%)$} \\
\hline MP & $168.6 \pm 11.6$ & $151.5 \pm 7.9$ & $149.6 \pm 8.9$ & $179.9 \pm 17.7^{\#}$ \\
\hline PLA & $169.9 \pm 13.4$ & $158.7 \pm 15.4$ & $161.1 \pm 14.2$ & $153.8 \pm 12.4$ \\
\hline
\end{tabular}

Peak RFD = Peak rate of force development during take-off phase. Mean RFD = average rate of force development during take-off phase. $\mathrm{H}_{\text {max }} /$ $\mathrm{H}_{\text {min }}=$ Relation between jumping height and extent of countermovement. ANOVA with Bonferroni post-hoc: ${ }^{*},{ }^{*} *=$ Significantly different from Pre $(p<0.05, p<0.01), \wedge=$ Significantly different between groups $(p<0.05)$. Unpaired $t$-test: \# = Pre to Post change significantly different between groups $(p<0.05)$. Data are mean \pm standard error of the mean. 
- Table 5 Comprehensive metabolic panel.

\begin{tabular}{|c|c|c|c|c|c|}
\hline & \multicolumn{2}{|c|}{ MP } & \multicolumn{2}{|c|}{ PLA } & \multirow[b]{2}{*}{ p-value } \\
\hline & PRE & POST & PRE & POST & \\
\hline Glucose (mg/dL) & $90.3 \pm 1.9$ & $94.3 \pm 3.6$ & $89.3 \pm 2.7$ & $91.3 \pm 3.4$ & 0.672 \\
\hline BUN (mg/dL) & $14.8 \pm 1.1$ & $15.1 \pm 1.9$ & $13.3 \pm 1.1$ & $13.8 \pm 1.2$ & 0.902 \\
\hline Creatinine (mg/dL) & $0.9 \pm 0.1$ & $1.0 \pm 0.1$ & $0.9 \pm 0.0$ & $0.9 \pm 0.1$ & 0.189 \\
\hline Sodium (mmol/L) & $141.0 \pm 0.5$ & $141.4 \pm 0.4$ & $141.8 \pm 0.6$ & $141.5 \pm 0.9$ & 0.316 \\
\hline Potassium (mmol/L) & $4.2 \pm 0.1$ & $4.3 \pm 0.1$ & $4.3 \pm 0.0$ & $4.6 \pm 0.1$ & 0.405 \\
\hline Chloride (mmol/L) & $104.9 \pm 0.6$ & $105.1 \pm 0.5$ & $105.2 \pm 0.7$ & $105.2 \pm 0.4$ & 0.851 \\
\hline $\mathrm{CO}_{2}(\mathrm{mmol} / \mathrm{L})$ & $28.2 \pm 0.6$ & $27.5 \pm 0.5$ & $28.7 \pm 0.5$ & $28.9 \pm 0.3$ & 0.207 \\
\hline Calcium (mg/dL) & $9.3 \pm 0.1$ & $9.0 \pm 0.1$ & $9.2 \pm 0.2$ & $9.2 \pm 0.1$ & 0.323 \\
\hline Total Protein (g/dL) & $7.2 \pm 0.1$ & $6.9 \pm 0.1$ & $7.3 \pm 0.2$ & $7.1 \pm 0.1$ & 0.781 \\
\hline Albumin (g/dL) & $4.3 \pm 0.1$ & $4.4 \pm 0.1$ & $4.4 \pm 0.1$ & $4.4 \pm 0.1$ & 0.990 \\
\hline Globulin (g/dL) & $2.9 \pm 0.1$ & $2.6 \pm 0.1$ & $2.9 \pm 0.1$ & $2.7 \pm 0.1$ & 0.586 \\
\hline Bilirubin (mg/dL) & $0.7 \pm 0.1$ & $0.7 \pm 0.1$ & $0.9 \pm 0.2$ & $0.8 \pm 0.2$ & 0.541 \\
\hline Alkaline Phosphate (IU/L) & $59.3 \pm 4.3$ & $61.4 \pm 3.5$ & $64.4 \pm 6.8$ & $68.9 \pm 8.4$ & 0.494 \\
\hline ALT (IU/L) & $22.6 \pm 3.9$ & $26.2 \pm 4.4$ & $25.0 \pm 2.6$ & $26.7 \pm 4.0$ & 0.569 \\
\hline AST (IU/L) & $25 \pm 2.5$ & $26.5 \pm 2$ & $27.3 \pm 3.2$ & $26.3 \pm 2.4$ & 0.304 \\
\hline Albumin: Globulin & $1.5 \pm 0.1$ & $1.7 \pm 0.1$ & $1.5 \pm 0.1$ & $1.7 \pm 0.1$ & 0.759 \\
\hline BUN: Creatinine & $17.4 \pm 0.8$ & $15.1 \pm 0.9$ & $15.1 \pm 1.0$ & $15.2 \pm 1.2$ & 0.071 \\
\hline
\end{tabular}

> Table 6 Complete blood count.

\begin{tabular}{|c|c|c|c|c|c|}
\hline & \multicolumn{2}{|c|}{ MP } & \multicolumn{2}{|c|}{ PLA } & \multirow[b]{2}{*}{ p-value } \\
\hline & PRE & POST & PRE & POST & \\
\hline WBC (K/uL) & $4.6 \pm 0.4$ & $4.6 \pm 0.3$ & $4.3 \pm 0.3$ & $4.5 \pm 0.4$ & 0.405 \\
\hline RBC (M/uL) & $4.5 \pm 0.2$ & $4.4 \pm 0.2$ & $4.5 \pm 0.1$ & $4.5 \pm 0.1$ & 0.595 \\
\hline Hemoglobin (g/dL) & $13.4 \pm 0.7$ & $13.2 \pm .07$ & $14 \pm 0.3$ & $13.9 \pm 0.4$ & 0.833 \\
\hline Hematocrit (\%) & $43.3 \pm 1.8$ & $40.7 \pm 1.8$ & $45.0 \pm 0.9$ & $43.1 \pm 1.0$ & 0.561 \\
\hline MCV (fl) & $95.8 \pm 2.8$ & $91.8 \pm 2.5$ & $99.2 \pm 1.7$ & $95.4 \pm 1.7$ & 0.793 \\
\hline $\mathrm{MCH}(\mathrm{pg})$ & $29.6 \pm 1.1$ & $29.7 \pm 1.1$ & $30.9 \pm 0.7$ & $30.8 \pm 0.7$ & 0.328 \\
\hline MCHC (g/dL) & $30.9 \pm 0.4$ & $32.2 \pm 0.4$ & $31.2 \pm 0.2$ & $32.2 \pm 0.2$ & 0.244 \\
\hline RDW (\%) & $16 \pm 0.6$ & $15.1 \pm 0.6$ & $15.1 \pm 0.2$ & $14.2 \pm 0.2$ & 0.823 \\
\hline Platelet Count (k/uL) & $238.8 \pm 21.0$ & $223.4 \pm 19.8$ & $218.1 \pm 7.8$ & $228.3 \pm 9.0$ & 0.056 \\
\hline MPV (fl) & $9.0 \pm 0.4$ & $9.4 \pm 0.4$ & $8.6 \pm 0.2$ & $9.0 \pm 0.3$ & 0.932 \\
\hline
\end{tabular}

\section{Serum Creatine Kinase (CK) concentration}

All conditions demonstrated greater CK concentration compared to control ( $p<0.05$, > Fig. 4) while both supplement arms demonstrated lower CK levels compared to the exercise arm $(p<0.05)$. Additionally, CK concentration was significantly lower in E + MP2 compared to E + MP1 $(p<0.05)$.

\section{Discussion}

The results of this study indicate that $25 \mathrm{mg}$ of daily marine phytoplankton (microalga Tetraselmis chuii, [MP]) supplementation improved long-term recovery during a 5-week training program de- signed to induce non-functional overreaching. We also found that MP supplementation better preserved explosive strength following a non-functional overreaching cycle compared to the PLA group. In addition, no undesirable changes in blood chemistry or hematology were found following MP supplementation. Furthermore, MP supplementation increased positive (NCAM and MyoD) and decreased negative (myostatin, MuRF-1, MAFbx) myogenic factors regulating satellite cell proliferation in exercising rats. These findings confirm our hypotheses about supplementation with marine phytoplankton.

Generally speaking, performance following muscle damaging exercise recovers within 72 to $96 \mathrm{~h}$ [28]. Explosive strength, as 
- Table 7 Automated differential cell count.

\begin{tabular}{|l|c|c|c|c|c|}
\hline & \multicolumn{2}{|c|}{ MP } & \multicolumn{2}{c|}{ PLA } & POST \\
\hline & PRE & POST & PRE & $51.6 \pm 2.1$ & 0.733 \\
\hline Granulocyte (\%) & $56.4 \pm 2.7$ & $55.0 \pm 2.4$ & $52.9 \pm 2.0$ & $36.9 \pm 2.2$ & 0.653 \\
\hline Lymphocyte (\%) & $35.3 \pm 2.0$ & $34.7 \pm 2.0$ & $37.1 \pm 1.8$ & $7.1 \pm 0.4$ & 0.479 \\
\hline Monocyte (\%) & $5.7 \pm 0.7$ & $7.6 \pm 0.5$ & $5.9 \pm 0.3$ & $4.0 \pm 0.7$ & 0.389 \\
\hline Eosinophil (\%) & $2.2 \pm 0.5$ & $2.2 \pm 0.8$ & $3.6 \pm 0.7$ & $0.5 \pm 0.1$ & 0.867 \\
\hline Basophil (\%) & $0.5 \pm 0.1$ & $0.5 \pm 0.1$ & $0.5 \pm 0.1$ & $2.4 \pm 0.3$ & 0.429 \\
\hline Granulocyte \# (K/uL) & $2.7 \pm 0.3$ & $2.5 \pm 0.2$ & $1.6 \pm 0.1$ & $0.3 \pm 0.0$ & 0.404 \\
\hline Lymphocyte \# (K/uL) & $1.6 \pm 0.1$ & $1.5 \pm 0.1$ & $0.3 \pm 0.0$ & $0.2 \pm 0.0$ & 0.389 \\
\hline Monocyte \# (K/uL) & $0.2 \pm 0.0$ & $0.3 \pm 0.0$ & $0.2 \pm 0.0$ & $0.0 \pm 0.0$ & n/a \\
\hline Eosinophil \# (K/uL) & $0.1 \pm 0.0$ & $0.1 \pm 0.0$ & $0.0 \pm 0.0$ & & \\
\hline Basophil \# (K/uL) & $0.0 \pm 0.0$ & $0.0 \pm 0.0$ & & \\
\hline P-value = group by time probability value from two-way mixed model ANOVA. Data are mean \pm standard error of the mean.
\end{tabular}

a

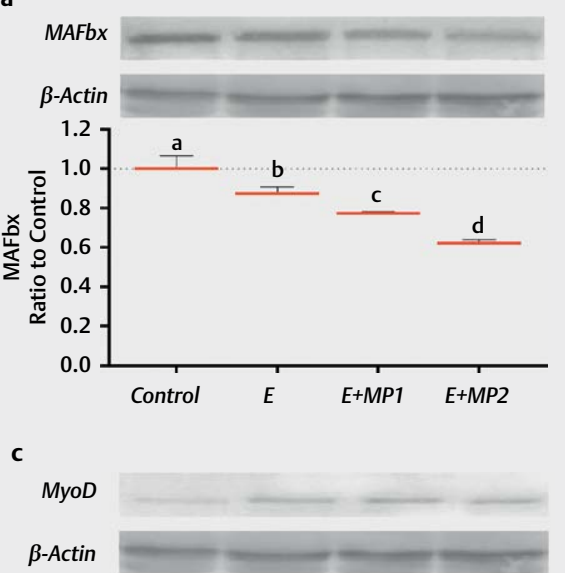

b

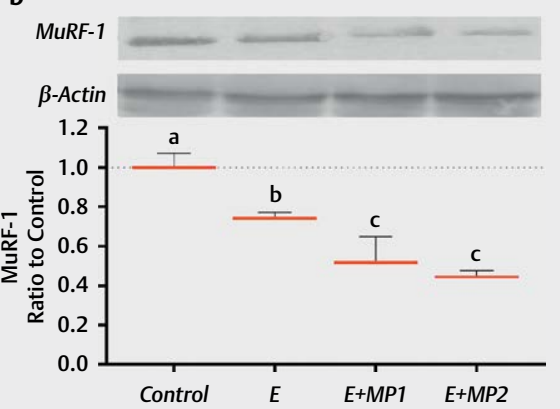

d

Myostatin

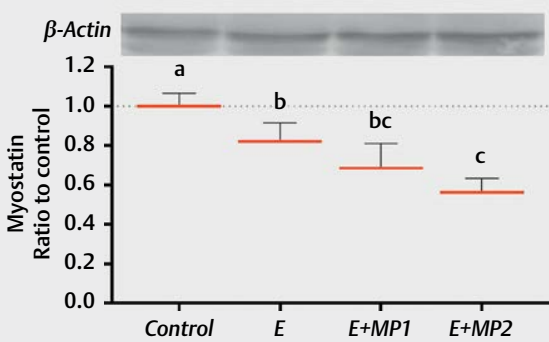

e

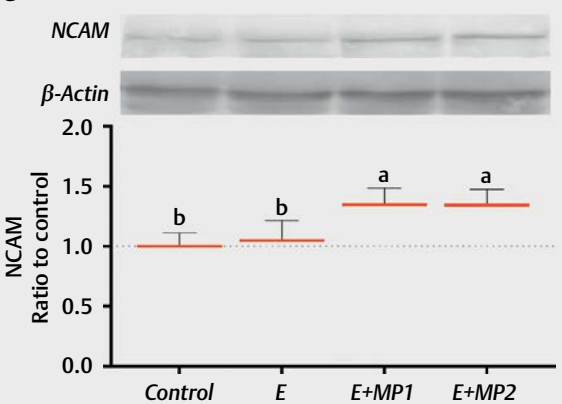

- Fig. 3 Effects of Marine Phytoplankton on muscle MAFbx a, MuRF-1 b, MyoD c, Myostatin d, and NCAM e levels in treadmill running rats. The densitometric analysis of the relative intensity according to the control group of the western blot bands was performed with $\beta$-actin normalization to ensure equal protein loading. The error bars above the lines point out the standard deviation of the mean. Different symbols (a-d) indicate statistical differences among the groups (ANOVA and Turkey's post-hoc test; $\mathrm{p}<0.05$ ). MAFbx = Muscle atrophy F-box; MuRF-1 = Muscle RING-finger protein-1; MyoD $=$ Myogenic differentiation factor; NCAM = Neural cell adhesion molecules. 


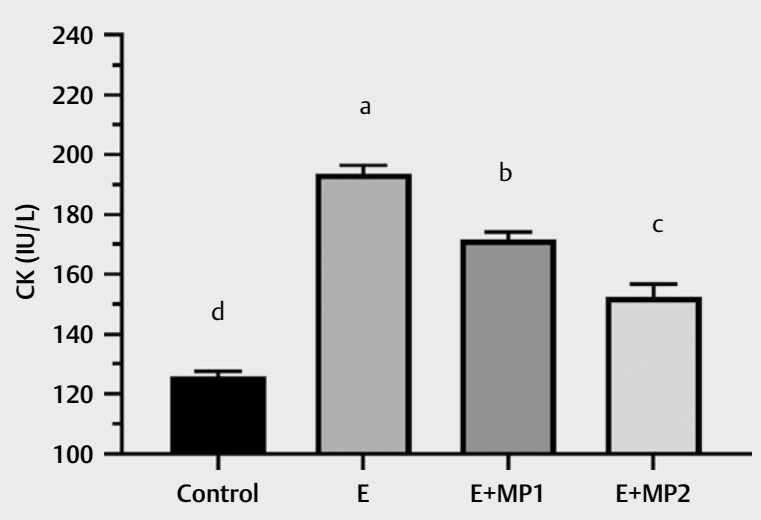

- Fig. 4 Serum Creatine Kinase Concentration. Serum creatine kinase (CK) concentration across all four arms. Data are expressed as mean and standard error of the mean. Different symbols (a-d) indicate statistical differences among the groups (ANOVA and Turkey's post-hoc test; $\mathrm{p}<0.05$ ).

shown by rate of force development (RFD), was reduced at Wk2Post and Wk5-Post. Moreover, in the PLA condition, these changes remained depressed for seven days following the final overreaching phase of the study. These findings indicate that the resistancetraining program induced mild non-functional overreaching in the PLA. However, explosive strength had recovered in the MP group suggesting that marine phytoplankton supplementation normalized recovery to that seen with typical muscle damaging protocols. These findings indicate that the training program successfully imposed a mild non-functional overreaching stimulus that was substantiated by levels of fatigue that remained for at least a week following strenuous training, and that MP supplementation was able to aid in the recovery of explosive strength.

Overreaching can be viewed on a continuum form mild to severe symptoms [28]. When observing jump displacement and peak force output, no significant between- or within-group differences were indicated despite significant changes in explosive strength. Due to the symptomology not including these changes we can suggest that the level of overreaching induced by the training program was mild and not severe. However, there are plausible explanations for the lack of changes in force metrics and jump displacement in our study. The first possible explanation for these outcomes may be due to storage and reutilization of elastic energy [29, 30]. During the countermovement jump, active muscle is pre-stretched, and energy is absorbed and temporarily stored in passive elastic components to be reused upon concentric contraction. This series of events could allow subjects to overcome fatigue and sustain force-generation capacity in a countermovement jump [31, 32]. These findings are corroborated by previous literature reporting no significant changes in force-generation capacity during the countermovement jump following fatiguing physical activity [33-35].

An additional explanation for similar performance (jump displacement and peak force) in the countermovement jump, despite differences in RFD, are changes in the efficiency of the jump between conditions. In our study, efficiency was inferred by the ratio between jumping height and the extent of the countermovement
$\left(\mathrm{H}_{\max } / \mathrm{H}_{\min }\right)$. It appears that the change in efficiency from Pre to Post in the MP group was greater than PLA. This data suggest that the PLA group increased the magnitude of the countermovement without demonstrating increases in jumping height. Thus, it is possible that the PLA group exhibited this performance behavior as a means to overcome neuromuscular fatigue (e. g., decrements in RFD). Specifically, increasing the extent of the countermovement could promote neuromuscular compensatory mechanisms such as increasing motor unit recruitment and modulating the motor unit firing rate [36-38]. Furthermore, increased countermovement could trigger stronger stretch reflexes [39], promote more cross bridge formation [40] and induce longer latency responses to enhance muscle stimulation [41]; all of which can enhance force development and strengthen muscle contraction in the lower-body extensors prior to shortening of the concentric phase [29,40].

Exercise-induced fatigue can occur both peripherally and centrally. Peripheral fatigue occurs primarily in skeletal muscle and is exacerbated by depletion of energy stores, accumulation of metabolic byproducts, and muscle damage from mechanical and chemical disturbances [42]. On the other hand, central fatigue is simply considered a reduction in the ability to maximally activate a given muscle [43]. This type of fatigue can be mediated by group III and IV afferent feedback loops [44], increased BCAA metabolism [3], and increased motor cortex excitability [43].

The impairment in explosive strength performance combined with the reduction in perceived recovery allows us to theorize that A) the training program was sufficient at inducing neuromuscular (central) fatigue, and, B) the subjects completed the post-testing protocol in a state of neuromuscular and/or central fatigue. This hypothesis follows the findings that explosive strength is better able to detect both acute (24-72 hrs) [18] and chronic (>4 weeks) [20] changes in neuromuscular function as compared to less-time constrained peak force measures.

Since ameliorating the accumulation of fatigue and promoting recovery is of great interest to athletes, it is worth exploring how supplementation with the marine phytoplankton-derived microalga Tetraselmis chuii may influence these variables. From a molecular standpoint, recovery is controlled by a complex array of myogenic regulatory factors that drive satellite cell activation, differentiation, and replenishment $[11,12]$. Indeed, research has indicated satellite cells as the key variable driving recovery from exercise $[13,14]$. Impairment in the recruitment of these cells ultimately leads to a failing ability to compensate for training load-induced stress $[13,15]$. Key positive regulators of satellite cell cycle progression include MyoD and NCAM, a multifunctional cell-surface protein that has been found to drive muscle recovery [16]. In contrast, myostatin impairs muscle recovery by inhibiting satellite cell progression and increasing protein breakdown [17]. Muscle damaging exercise can induce a robust myogenic regulatory response that facilitates regeneration. This response occurs via the activation, proliferation, and late stage differentiation of satellite cells to fuse to and repair skeletal muscle.

The importance of nutritional status in regulating these regenerative processes has been demonstrated. Nutrients high in antioxidants may buffer elevated levels of reactive oxygen species and reduce oxidative stress in muscles, thereby favoring satellite cell differentiation and proliferation [45]. In addition, research has dem- 
onstrated that essential fatty acids may modulate the myogenic program of the stem cell population within skeletal muscles and therefore speed exercise recovery $[46,47]$. This unique marine phytoplankton ingredient is high in fatty acids and antioxidant enzymes such as SOD. In fact, our previous research demonstrated that marine phytoplankton supplementation directly increased an array of intramuscular antioxidant enzymes [24]. These findings led us to hypothesize that it may improve skeletal muscle regeneration.

In order to explore a mechanism of action for exercise recovery, we implemented a rat model in which the exercise protocol significantly increased serum CK concentration, indicating the occurrence of muscle damage. Marine phytoplankton supplementation demonstrated the ability to reduce the elevation of CK concentration from exercise in a dose dependent manner. Additionally, the rat model supports our hypotheses that marine phytoplankton supplementation was able to increase the expression of early (MyoD) and late (NCAM) cell cycle regulators. While exercise alone was able to increase early expression, it did not elevate late cell cycle parameters. These findings indicate an incomplete regenerative response that is characteristic of overreaching and slowed recovery. Additionally, supplementation was also able to depress myostatin expression. It is known that the interaction of myostatin with its receptor increases muscle degradation through activating the ubiquitin pathway [48]. Skeletal muscle recovery is largely impaired by the ubiquitin-proteasome and autophagy-lysosomal systems. The ubiquitin-proteasome ligases targeting proteins for degradation are MAFbx and MuRF1 [49]. Therefore, as expected, the expression of these downstream ubiquitin rate limiting E3 ligases were depressed in the present study. These findings suggest that marine phytoplankton may improve recovery through a combination of optimized cell cycle regulation, improved protein turnover, and mitigation of muscle damage indices.

There are some notable limitations to this study. Subjects were instructed to maintain their typical eating habits (e. g. eat the same number of meals with the same meal schedule) and avoid drastic changes in diet types. However, dietary intake was not tracked, therefore we have no data to present here. Additionally, other habits potentially impacting recovery, such as sleep and non-exercise related activity outside of the laboratory, were not monitored. Next, in the human model, we did not evaluate common inflammatory [50-53], immune [9, 54-57], or hormonal biomarkers [5862 ] used in previous research to evaluate training stress and recovery. While no single biomarker exist to reliably detect overreaching [28], including such a measure would have permitted a more comprehensive evaluation of the subject's physiological state.

\section{Conclusions}

We can conclude that the training program was effective at inducing a state of neuromuscular fatigue. However, marine phytoplankton supplementation was able to improve long-term recovery perceptually and functionally via explosive strength following this fatiguing period. Since recovery can be defined as, "returning what was lost due to exercise" [63], we have shown that marine phytoplankton supplementation can improve exercise recovery following non-functional overreaching in a human model. Mechanistical- ly, these changes appear to be driven through cell cycle regulation and a potential to improve protein turnover. Finally, it was demonstrated that the ingredient had no negative impact on any blood safety parameter examined. These findings have direct nutritional and supplementation implications by providing practitioners with additional strategies for improving recovery during periods of high physiological stress.

\section{Funding}

Lonza Consumer Health Inc. supplied treatment (Oceanix TM) and placebo conditions, and financially support the study.

\section{Conflict of Interests}

Shane Durkee is employed by Lonza Consumer Health Inc. He was not involved in data collection, data curation, or formal statistical analysis. All other authors report no conflict of interests.

\section{References}

[1] Busso T. Variable dose-response relationship between exercise training and performance. Med Sci Sports Exerc 2003; 35: 1188-1195

[2] Radak Z, Chung HY, Goto S. Exercise and hormesis: oxidative stress-related adaptation for successful aging. Biogerontology 2005; 6: 71-75

[3] Meeusen R, Watson P, Hasegawa $\mathrm{H}$ et al. Central fatigue: the serotonin hypothesis and beyond. Sports Med 2006; 36: 881-909

[4] Coutts A, Reaburn P, Piva T] et al. Changes in selected biochemical, muscular strength, power, and endurance measures during deliberate overreaching and tapering in rugby league players. Int J Sports Med 2007; 28: 116-124

[5] Kraemer W], French DN, Paxton NJ et al. Changes in exercise performance and hormonal concentrations over a big ten soccer season in starters and nonstarters. J Strength Cond Res 2004; 18 : $121-128$

[6] Naessens G, Chandler T], Kibler WB et al. Clinical usefulness of nocturnal urinary noradrenaline excretion patterns in the follow-up of training processes in high-level soccer players. J Strength Cond Res 2000; 14: 125-131

[7] Hoffman JRP, Kaminsky M. Use of performance testing for monitoring overtraining in elite youth basketball players. Strength Cond J 2000; 22: 54-62

[8] Moore CA, Fry AC. Nonfunctional overreaching during off-season training for skill position players in collegiate American football. J Strength Cond Res 2007; 21: 793-800.

[9] Coutts AJ, Wallace LK, Slattery KM. Monitoring changes in performance, physiology, biochemistry, and psychology during overreaching and recovery in triathletes. Int J Sports Med 2007; 28: 125-134

[10] Slattery K, Bentley D, Coutts A]. The role of oxidative, inflammatory and neuroendocrinological systems during exercise stress in athletes: Implications of antioxidant supplementation on physiological adaptation during intensified physical training. Sports Med 2015; 45: 453-471

[11] Kadi F, Charifi N, Denis C et al. The behaviour of satellite cells in response to exercise: What have we learned from human studies? Pflugers Arch 2005; 451: 319-327 
[12] Rathbone CR, Wenke JC, Warren GL et al. Importance of satellite cells in the strength recovery after eccentric contraction-induced muscle injury. Am J Physiol Regul Integr Comp Physiol 2003; 285: R1490-R1495

[13] Cheng AJ, Jude B, Lanner JT. Intramuscular mechanisms of overtraining. Redox Biol 2020; 35: 101480

[14] Joanisse S, Snijders T, Nederveen JP et al. The impact of aerobic exercise on the muscle stem cell response. Exerc Sport Sci Rev 2018; 46: $180-187$

[15] Paulsen G, Mikkelsen UR, Raastad T et al. Leucocytes, cytokines and satellite cells: What role do they play in muscle damage and regeneration following eccentric exercise? Exerc Immunol Rev 2012; 18: 42-97

[16] Zammit PS. Function of the myogenic regulatory factors Myf5, MyoD, Myogenin and MRF4 in skeletal muscle, satellite cells and regenerative myogenesis. Semin Cell Dev Biol 2017; 72: 19-32

[17] Sharp MH, Lowery RP, Mobley CB et al. The effects of fortetropin supplementation on body composition, strength, and power in humans and mechanism of action in a rodent model. J Am Coll Nutr 2016; 35: 679-691

[18] Peñailillo L, Blazevich A, Numazawa $\mathrm{H}$ et al. Rate of force development as a measure of muscle damage. Scand J Med Sci Sports 2015; 25: 417-427

[19] Maffiuletti NA, Aagaard P, Blazevich AJ et al. Rate of force development: Physiological and methodological considerations. Eur J Appl Physiol 2016; 116: 1091-1116

[20] Hornsby WG, Gentles JA, MacDonald C] et al. Maximum strength, rate of force development, jump height, and peak power alterations in weightlifters across five months of training. Sports (Basel) 2017; 5: 78

[21] Sikorski EM, Wilson JM, Lowery RP et al. Changes in perceived recovery status scale following high-volume muscle damaging resistance exercise. J Strength Cond Res 2013; 27: 2079-2085

[22] Laurent CM, Green JM, Bishop PA et al. A practical approach to monitoring recovery: Development of a perceived recovery status scale. J Strength Cond Res 2011; 25: 620-628

[23] Graeff-Hönninger S, Khajehei F. The demand for superfoods: Consumers' desire, production viability and bio-intelligent transition. In: Piatti C, Graeff-Hönninger S, Khajehei F, Eds. Food Tech Transitions: Reconnecting Agri-Food, Technology and Society. Springer International Publishing 2019: 81-94

[24] Sharp M, Sahin K, Stefan M et al. Phytoplankton supplementation lowers muscle damage and sustains performance across repeated exercise bouts in humans and improves antioxidant capacity in a mechanistic animal. Nutrients 2020; 12: 1990

[25] Harriss DJ, MacSween A, Atkinson G. Ethical standards in sport and exercise science research: 2020 Update. Int J Sports Med 2019; 40: 813-817

[26] Mazzetti SA, Kraemer W], Volek JS et al. The influence of direct supervision of resistance training on strength performance. Med Sci Sports Exerc 2000; 32: 1175-1184

[27] Liu Y-F, Chen H, Yu L et al. Upregulation of hippocampal TrkB and synaptotagmin is involved in treadmill exercise-enhanced aversive memory in mice. Neurobiol Learn Mem 2008; 90: 81-89

[28] Myrick KM. Overtraining and overreaching syndrome in athletes. J Nurse Pract 2015; 11: 1018-1022

[29] Asmussen E, Bonde-Petersen F. Storage of elastic energy in skeletal muscles in man. Acta Physiol Scand 1974; 91: 385-392

[30] Komi PV, Bosco C. Utilization of stored elastic energy in leg extensor muscles by men and women. Med Sci Sports 1978; 10: 261-265

[31] Harrison AJ, Gaffney SD. Effects of muscle damage on stretch-shortening cycle function and muscle stiffness control. J Strength Cond Res 2004; 18: 771-776
[32] Wilson JM, Flanagan EP. The role of elastic energy in activities with high force and power requirements: A brief review. J Strength Cond Res 2008; 22: 1705-1715

[33] Thorlund JB, Michalsik LB, Madsen K et al. Acute fatigue-induced changes in muscle mechanical properties and neuromuscular activity in elite handball players following a handball match. Scand J Med Sci Sports 2008; 18: 462-472

[34] Hoffman JR, Nusse V, Kang J. The effect of an intercollegiate soccer game on maximal power performance. Can J Appl Physiol 2003; 28: 807-817

[35] Johnston RD, Gibson NV, Twist C et al. Physiological responses to an intensified period of rugby league competition. J Strength Cond Res 2013; 27: 643-654

[36] Contessa P, Adam A, De Luca C]. Motor unit control and force fluctuation during fatigue. J Appl Physiol (1985) 2009; 107: 235-243

[37] Calder KM, Stashuk DW, McLean L. Physiological characteristics of motor units in the brachioradialis muscle across fatiguing low-level isometric contractions. J Electromyogr Kinesiol 2008; 18: 2-15

[38] McManus L, Hu X, Rymer WZ et al. Changes in motor unit behavior following isometric fatigue of the first dorsal interosseous muscle. J Neurophysiol 2015; 113: 3186-3196

[39] Dietz V, Schmidtbleicher D, Noth J. Neuronal mechanisms of human locomotion. J Neurophysiol 1979; 42: 1212-1222

[40] Bobbert MF, Gerritsen KG, Litjens MC et al. Why is countermovement jump height greater than squat jump height? Med Sci Sports Exerc 1996; 28: 1402-1412

[41] Jones GM, Watt DGD. Observations on the control of stepping and hopping movements in man. J Physiol 1971; 219: 709-727

[42] Zając A, Chalimoniuk M, Maszczyk A et al. Central and peripheral fatigue during resistance exercise - a critical review. J Hum Kinet 2015; 49: 159-169

[43] Löscher WN, Nordlund MM. Central fatigue and motor cortical excitability during repeated shortening and lengthening actions. Muscle Nerve 2002; 25: 864-872

[44] Amann M, Sidhu SK, Weavil JC et al. Autonomic responses to exercise: group III/IV muscle afferents and fatigue. Auton Neurosci 2015; 188: 19-23

[45] Alway SE, Bennett BT, Wilson JC et al. Epigallocatechin-3-gallate improves plantaris muscle recovery after disuse in aged rats. Exp Gerontol 2014; 50: 82-94

[46] Jakeman JR, Lambrick DM, Wooley B et al. Effect of an acute dose of omega-3 fish oil following exercise-induced muscle damage. Eur J Appl Physiol 2017; 117: 575-582

[47] Bhullar AS, Putman CT, Mazurak VC. Potential role of omega-3 fatty acids on the myogenic program of satellite cells. Nutr Metab Insights 2016; 9: 1-10

[48] Allen DL, Hittel DS, McPherron AC. Expression and function of myostatin in obesity, diabetes, and exercise adaptation. Med Sci Sports Exerc 2011; 43: 1828-1835

[49] Bodine SC, Latres E, Baumhueter $S$ et al. Identification of ubiquitin ligases required for skeletal muscle atrophy. Science 2001; 294: 1704-1708

[50] Joro R, Uusitalo A, DeRuisseau KC et al. Changes in cytokines, leptin, and IGF-1 levels in overtrained athletes during a prolonged recovery phase: A case-control study. J Sports Sci 2017; 35: 2342-2349

[51] Moldoveanu Al, Shephard R], Shek PN. The cytokine response to physical activity and training. Sports Med 2001; 31: 115-144

[52] Andersson H, Bøhn SK, Raastad T et al. Differences in the inflammatory plasma cytokine response following two elite female soccer games separated by a 72-h recovery. Scand J Med Sci Sports 2010; 20: 740-747 
[53] Davis JM, Murphy EA, Carmichael MD et al. Curcumin effects on inflammation and performance recovery following eccentric exercise-induced muscle damage. Am J Physiol Regul Integr Comp Physiol 2007; 292: R2168-R2173

[54] Gleeson M. Immune function in sport and exercise. J Appl Physiol (1985) 2007; 103: 693-699

[55] Fahlman MM, Engels H-J. Mucosal IgA and URTI in American college football players: A year longitudinal study. Med Sci Sports Exerc 2005; 37: $374-380$

[56] Mackinnon LT, Hooper S. Mucosal (secretory) immune system responses to exercise of varying intensity and during overtraining. Int J Sports Med 1994; 15: S179-S183

[57] Halson S, Lancaster G, Jeukendrup A et al. Immunological responses to overreaching in cyclists. Med Sci Sports Exerc 2003; 35: 854-861

[58] Hayes LD, Grace FM, Baker JS et al. Exercise-induced responses in salivary testosterone, cortisol, and their ratios in men: a meta-analysis. Sports Med 2015; 45: 713-726
[59] Anderson T, Haake S, Lane AR et al. CHANGES in resting salivary testosterone, cortisol and interleukin- 6 as biomarkers of overtraining. Balt J Sport Health Sci 2016; 101: 2-7

[60] Fry AC, Kraemer W], Stone MH et al. Endocrine and performance responses to high volume training and amino acid supplementation in elite junior weightlifters. Int J Sport Nutr 1993; 3: 306-322

[61] Fry AC, Kraemer W], Stone MH et al. Endocrine responses to overreaching before and after 1 year of weightlifting. Can J Appl Physiol 1994; 19: 400-410

[62] Häkkinen K, Keskinen KL, Alén M et al. Serum hormone concentrations during prolonged training in elite endurance-trained and strengthtrained athletes. Eur J Appl Physiol 1989; 59: 233-238

[63] Sands WA. Chapter 18: Thinking sensibly about recovery. In: Strength and Conditioning for Sports Performance. Routledge; New York, NY: 2016: 451-483 